\title{
Giant duodenal ulcers after neurosurgery for brainstem tumors that required reoperation for gastric disconnection: a report of two cases
}

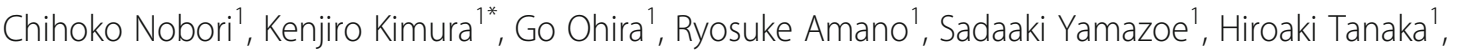 \\ Kentaro Naito², Toshihiro Takami ${ }^{2}$, Kosei Hirakawa' and Masaichi Ohira' ${ }^{1}$
}

\begin{abstract}
Background: Despite the efficacy of pharmacotherapy for gastrointestinal ulcers, severe cases of bleeding or perforation due to gastrointestinal ulcers still occur. Giant duodenal ulcer perforation is an uncommon but difficultto-manage pathology with a high mortality rate. We report two cases of giant duodenal ulcer perforation after neurosurgery for brainstem tumors that needed reoperation for gastric disconnection because of postoperative leakage and bleeding.

Case presentation: Both cases had undergone neurosurgery for brainstem tumors, and the patients were in a shock state for several days with peritonitis due to giant duodenal perforation. In Case 1, antrectomy with Billroth II reconstruction was performed. However, reoperation for gastric disconnection was needed because of major leakage of gastrojejunostomy and jejunojejunostomy. In Case 2, an omental patch, cholecystectomy, and insertion of a bile drainage tube from the cystic duct were performed for the giant duodenal ulcer, but leakage and bleeding from the ulcer edge required reoperation for gastric disconnection.

Conclusions: Brainstem tumors in these cases might have been related to duodenal ulcer perforation with late diagnosis that progressed to severe sepsis. For giant duodenal ulcer perforation with poor general condition, simple closure including omental patch or antrectomy with reconstruction is hazardous. Antrectomy with gastric disconnection, meaning gastrostomy, duodenostomy, feeding jejunostomy and cholecystectomy, is recommended.
\end{abstract}

Keywords: Giant duodenal ulcer, Gastric disconnection, Brainstem tumor

\section{Background}

Cushing reported gastroduodenal ulcers produced by elevated intracranial pressure caused by an intracranial tumor, head injury, or other space-occupying lesion, which have been called Cushing's ulcer [1]. The use of histamine H2-receptor antagonists or proton pump inhibitors can decrease the incidence of Cushing's ulcer and its complications, such as bleeding and perforation. However, cases of severe bleeding or perforation from gastroduodenal ulcers still occur. Generally, duodenal ulcer perforation is a

\footnotetext{
* Correspondence: kenjiro@med.osaka-cu.ac.jp

'Department of Surgical Oncology, Osaka City University Graduate School of Medicine, 1-4-3 Asahi-machi, Abeno-ku, Osaka, Japan

Full list of author information is available at the end of the article
}

surgical emergency. Factors such as advanced age, concomitant disease, preoperative shock, large size of the perforation, and delays in presentation and operation have been identified as risk factors for mortality from duodenal ulcer perforation [2]. Gapta et al. classified duodenal ulcer perforations into three groups based on the size of the perforations: 'small' perforations less than $1 \mathrm{~cm}$ in diameter; 'large' perforations more than $1 \mathrm{~cm}$ but less than $3 \mathrm{~cm}$ in diameter; and 'giant' perforations exceeding $3 \mathrm{~cm}$ [2]. Small and large perforations are common and relatively easy to manage, resulting in low mortality rates. On the other hand, giant perforations are uncommon but difficult to manage and associated with higher mortality rates. Simple closure or omental patching alone have been 
reported as unsafe. Two cases of giant duodenal ulcer perforation after neurosurgery that needed re-operation because of postoperative leakage and bleeding are described. Taking these cases into account, we discuss how to cope with perforation of a giant duodenal ulcer that has progressed to sepsis because of late diagnosis.

\section{Case presentations}

Case 1 involved a 25-year-old man who had undergone surgical resection of anaplastic ependymoma extending from the brainstem to the fourth ventricle (Fig. 1). Two days after neurosurgery, laboratory data showed an unexpectedly severe inflammatory response (white cell count, $18,900 / \mu \mathrm{L}$; C-reactive protein (CRP), $12.8 \mathrm{mg} / \mathrm{dl}$ ). The patient was observed with administration of meropenem.

Two days later, he developed shock and the abdomen appeared severely distended. Vital signs were: temperature, $39.1{ }^{\circ} \mathrm{C}$; heart rate, 130 beats $/ \mathrm{min}$; blood pressure, $73 /$ $37 \mathrm{mmHg}$ under medication with dopamine $8 \mu \mathrm{g} / \mathrm{kg} / \mathrm{min}$ and noradrenaline $0.25 \mu \mathrm{g} / \mathrm{kg} / \mathrm{min}$; and oxygen saturation, $94 \%$ in room air. Laboratory data showed: white cell

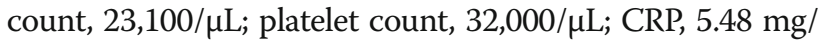
dL. Computed tomography (CT) showed free air and massive ascites (Fig. 2), and emergency surgery was performed under a presumptive diagnosis of gastrointestinal perforation. On laparotomy, $3 \mathrm{~L}$ of muddy ascites was removed, and a perforation $3.5 \mathrm{~cm}$ in diameter was found in the second portion of the duodenal bulb (Fig. 3). Antrectomy including the ulcerated portion using Billroth II reconstruction with Braun anastomosis, insertion of a duodenal drainage tube from the duodenal stump, and cholecystectomy with insertion of a bile drainage tube from the cystic duct were performed.

Ten days after the ulcer operation, major leakage of the gastrojejunostomy and jejunojejunostomy required re-operation, involving gastric disconnection, gastrostomy, duodenostomy, and feeding jejunostomy. After reoperation, the patient developed multiple-organ failure, but he recovered with intensive care. Eight months after the reoperation, digestive tract reconstruction surgery was performed using the Roux-en-Y method. Since that reconstruction surgery, the patient has been making satisfactory progress.

Case 2 involved a 62-year-old woman. She had undergone surgical resection of a brainstem hemangioblastoma that progressed acutely after stereotactic radiosurgery (Fig. 4). Six days after neurosurgery, laboratory data revealed an unexpectedly severe inflammatory response (white cell count, 23,100/ $\mu \mathrm{L}$; CRP, $18.5 \mathrm{mg} / \mathrm{dL}$ ). However, she was observed with administration of cefepime. After another 3 days, she developed shock and the abdomen appeared distended. Vital signs were: temperature, $38.1{ }^{\circ} \mathrm{C}$; heart rate, 140 beats/min; blood pressure, $60 / 40 \mathrm{mmHg}$ under medication with dopamine $10 \mu \mathrm{g} / \mathrm{kg} / \mathrm{min}$ and noradrenaline $0.15 \mu \mathrm{g} / \mathrm{kg} / \mathrm{min}$; and oxygen saturation, $92 \%$ in room air. Laboratory data showed: white cell count, 18,100/ $\mu \mathrm{L}$; platelet count, 29,000/ $\mu \mathrm{L} ; \mathrm{CRP}, 4.1 \mathrm{mg} / \mathrm{dL}$. CT showed massive ascites, but no free air at that time (Fig. 5). Aspirated ascites showed intestinal juice, so emergency surgery was performed under a diagnosis of gastrointestinal perforation.

On laparotomy, $4 \mathrm{~L}$ of biliary ascites was removed, and a perforation $4 \mathrm{~cm}$ in length was found at the duodenal bulb (Fig. 6). An omental patch over the perforation site, insertion of a drainage tube into the duodenum from the anterior wall of the stomach, and cholecystectomy with insertion of a bile drainage tube from the cystic duct were performed. Fifteen days after the ulcer operation, continuous bleeding at the wall edge of the duodenal ulcer required reoperation. Operative findings revealed ulcer bleeding and dehiscence of the perforation site. Gastric disconnection was performed, comprising antrectomy including resection of the ulcerated portion, tube duodenostomy, and tube gastrostomy. The patient also needed intensive care, and her condition improved after 3 months. However, digestive reconstruction surgery has not yet

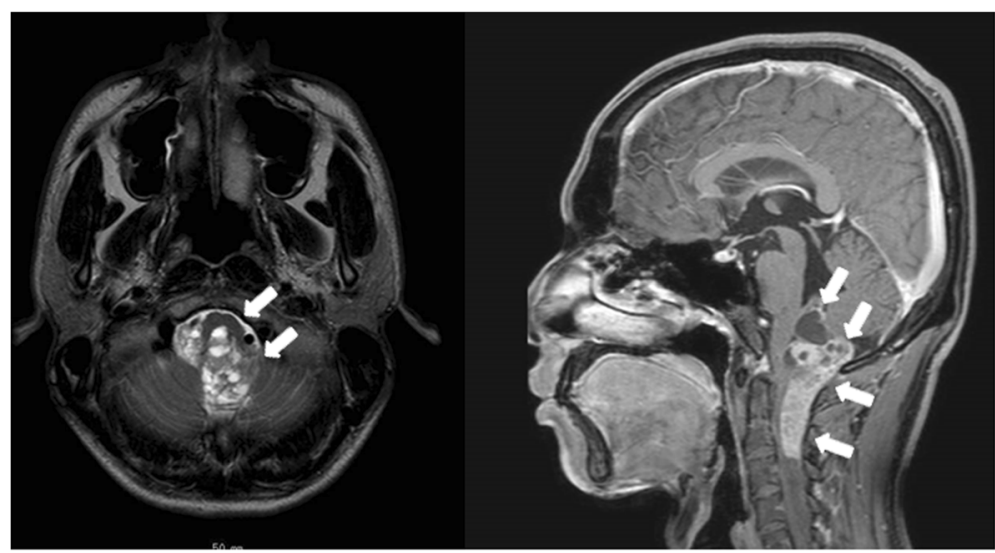

Fig. 1 Head MRI. The MRI scan reveals an anaplastic ependymoma that extended from brainstem to forth ventricle 


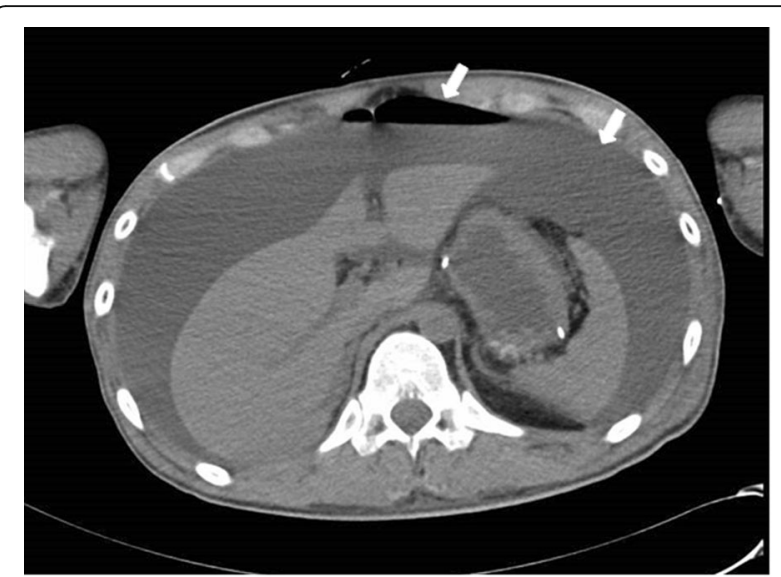

Fig. 2 Abdominal CT. The CT scan reveals a considerable amount of fluid and free air (arrow)

been performed as of the time of writing, as the brain tumor recurred during recovery.

\section{Discussion}

In these two cases, the brainstem tumors might have been related to duodenal ulcer perforation that progressed to septicemia. In 1841, Rokitansky suggested for the first time that ulcerative processes of the stomach might involve dysfunction of nervous mechanisms [3]. In 1932, Cushing reported gastroduodenal ulcers produced by elevated intracranial pressure caused by an intracranial tumor, head injury, or other space-occupying lesion. He suggested that such ulcerative processes might be related to diencephalic or brainstem disorders affecting the parasympathetic

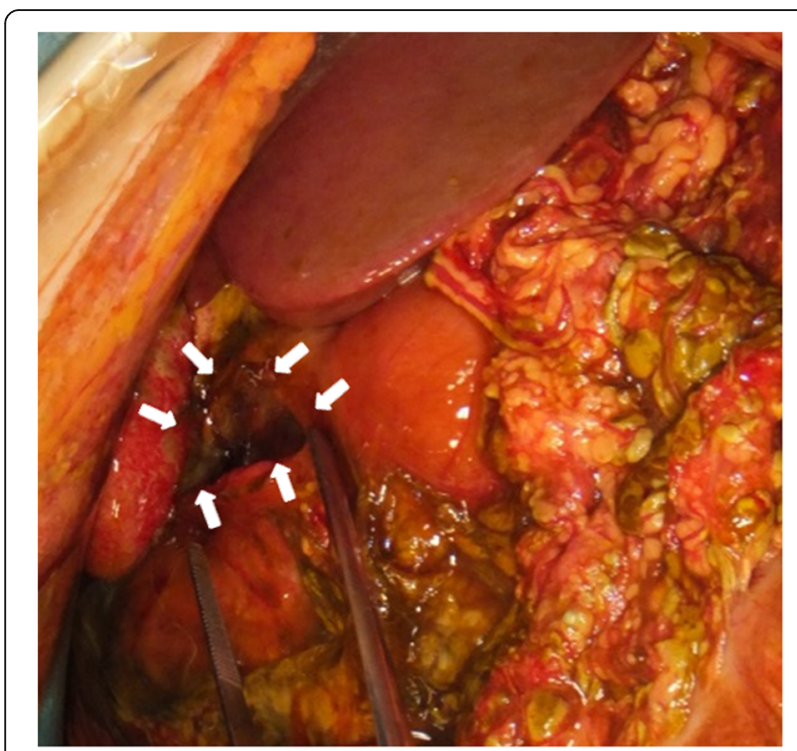

Fig. 3 The intra-operative finding. The perforation $3.5-\mathrm{cm}$ in diameter was found in the second portion of the duodenal bulb nervous system. Since then, ulcers of this type have been called Cushing's ulcers [1].

The mechanism of ulceration appears to involve three routes from the central nervous system to the stomach: 1) anterior hypothalamus - vagus nerve; 2) posterior hypothalamus - sympathetic nerve; and 3) posterior hypothalamus - anterior pituitary gland - adrenal cortex. Through these three routes, factors that aggravate the stomach are increased or protective factors are decreased. The sympathetic and parasympathetic nervous systems usually maintain a balance of the blood supply, gastric secretion, and gastric motility. Dysfunction of the central nervous system stimulates the hypothalamus, which then stimulates the sympathetic and parasympathetic nervous systems. Stimulation of sympathetic nerves decreases blood supply to the stomach, and stimulation of parasympathetic nerves increases gastric secretion. Moreover, adrenal cortical hormones through the anterior pituitary gland decrease gastric mucus secretion [4-10]. These factors then contribute to the development of gastroduodenal ulcers.

In general, factors such as advanced age, concomitant disease, preoperative shock, large size of the perforation, and delays in presentation and operation have been identified as risk factors for mortality in duodenal ulcer perforation [2]. Based on these factors, several scoring systems have been used to evaluate the condition of the patient with duodenal ulcer perforation, such as the Boey score [11], Mannheim Peritonitis Index [12-14], APACHE II score [15] and Jabalpur score [16]. In particular, the perforation-operation interval seems to represent an important factor for mortality. Mishra et al. reported that the mortality rate is $3 \%$ within $24 \mathrm{~h}, 57 \%$ from 25 to $72 \mathrm{~h}$, and $80 \%$ over $120 \mathrm{~h}$ after duodenal ulcer perforation [16]. Many reports have stated that an interval to operation larger than $24 \mathrm{~h}$ increases the mortality rate [17-19], because heavier bacterial contamination occurs in patients with delayed treatment [20]. In the present two cases, decreased level of consciousness was the major cause of delayed diagnosis in both patients. Although gauging the interval since ulcer perforation is difficult, at least $48 \mathrm{~h}$ may have elapsed in both cases, given the presence of septic shock. Of the above risk factors, our two cases showed large perforations, delayed diagnosis, concomitant disease, and preoperative shock, as well as advanced age in Case 2. Operations in such cases are generally difficult. Nonetheless, antrectomy with Billroth II reconstruction was performed for Case 1 and omental patching was performed for Case 2 . Because gastric disconnection requires a second operation for digestive reconstruction, we hesitated to perform this procedure, but gastric disconnection was unavoidable at the first emergency surgery.

Most duodenal ulcer perforations are less than $1 \mathrm{~cm}$ in length, and can be successfully treated with one-layer 


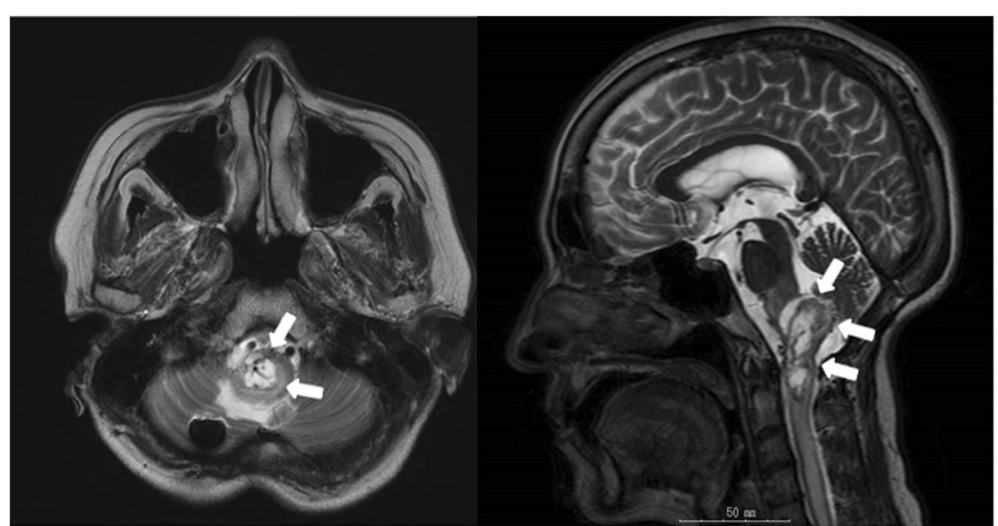

Fig. 4 Head MRI. The MRI scan reveals an a brainstem hemangioblastoma

closure plus a pedicled omental patch (Cellan-Jones technique) or an omental patch repair (Graham technique) [21-23]. On the other hand, giant duodenal ulcers are uncommon, with duodenal ulcer perforation more than $3 \mathrm{~cm}$ in length reportedly accounting for about $1.23 \%$ of cases [2]. Giant duodenal ulcers are difficult to manage and are associated with high rates of both morbidity (20$70 \%)$ and mortality (15-40 \%) because of the extensive duodenal tissue loss and surrounding tissue inflammation [24]. The Cellan-Jones and Graham techniques often fail to achieve closure of the perforation, resulting in postoperative leakage or gastric outlet obstruction.

Several reports have described surgical procedures for giant ulcers, including partial gastrectomy, jejunal serosal patch [25], free omental plug [26], and jejunal pedicle graft [27]. Lal et al. reported the efficacy of triple-tubeostomy (tube gastrostomy, retrograde tube duodenostomy, and feeding jejunostomy) with repair of the perforation for large duodenal ulcer perforations [28]. Cranford et al. advocated gastric disconnection with truncal vagotomy,

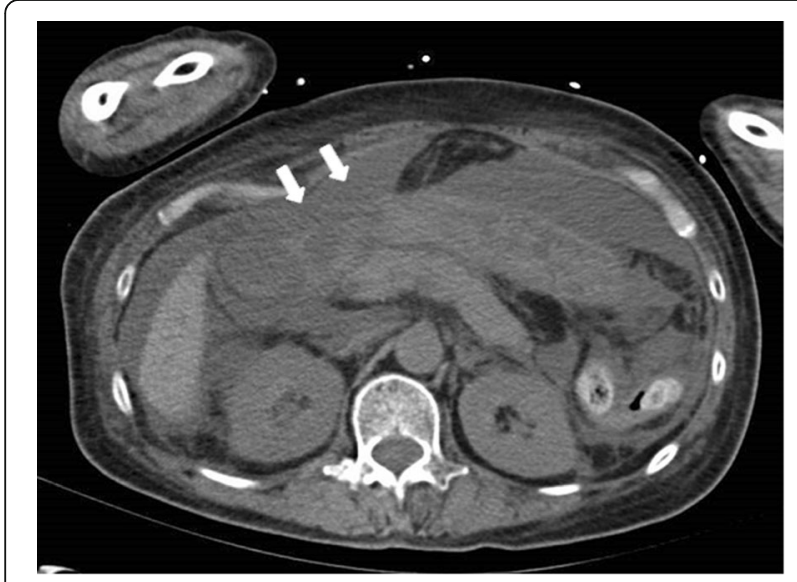

Fig. 5 Abdominal $C T$. The $\subset T$ scan reveals massive fluid accumulation and an irregular duodenal wall antrectomy, and triple-tube-ostomy [29]. This surgical approach is considered the most appropriate procedure for giant duodenal ulcer perforation in cases with poor general conditions owing to late diagnosis. Because one of the present cases showed bleeding and leakage from the repaired duodenal ulcer, antrectomy including the ulcerative portion was thought to be necessary for giant duodenal ulcer. In cases with poor general conditions owing to late diagnosis, digestive tract reconstruction is hazardous, and gastric disconnection might be needed. This approach necessitates a second elective operation for digestive reconstruction, but is thought to represent the safest procedure given the high mortality rate of this condition. Moreover, cholecystectomy with insertion of a bile drainage tube from the cystic duct might

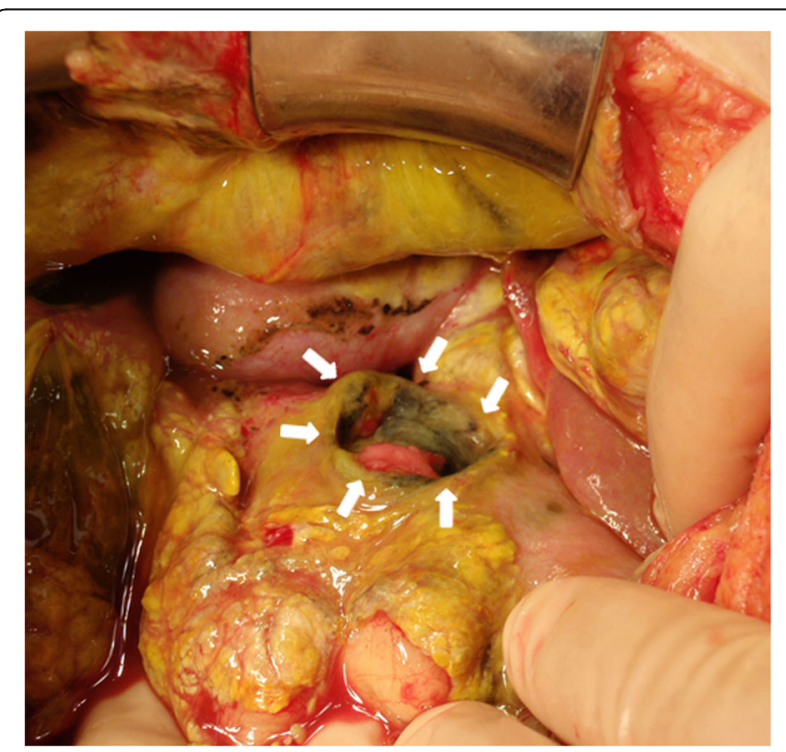

Fig. 6 The intra-operative finding. An 4-cm perforation was noted at the anterior wall of the duodenval bulb 
also be necessary in preparation for duodenal stump leakage.

\section{Conclusion}

We have reported two cases of giant duodenal ulcer perforation after neurosurgery that needed reoperations because of postoperative leakage and bleeding. For giant duodenal ulcer with poor general condition owing to late diagnosis, simple closure including omental patching or antrectomy with reconstruction is hazardous. Antrectomy with gastric disconnection, which means gastrostomy, duodenostomy, feeding jejunostomy and cholecystectomy, is recommended.

\section{Abbreviations}

CRP: C-reactive protein; CT: Computed tomography

\section{Acknowledgements}

None.

\section{Funding}

No funding was obtained for this study.

\section{Availability of data and materials}

The datasets supporting the conclusions of this article are included within the article.

\section{Authors' contributions}

$\mathrm{CN}, \mathrm{KK}$, and $\mathrm{GO}$ were involved in data collection, case analysis and writing the manuscript. RA, SY, HT, MO, and $\mathrm{KH}$ assisted in drafting the manuscript and reviewed the article. $\Pi$ and $\mathrm{KN}$ performed the first surgeries. All authors read and approved the final manuscript.

\section{Competing interests}

The authors declare that they have no competing interests.

\section{Consent for publication}

Written informed consent was obtained from the patients for publication of this case report and the accompanying images. A copy of written consent is available for review by the editor of this journal.

\section{Ethics approval and consent to participate}

Not applicable.

\section{Author details}

'Department of Surgical Oncology, Osaka City University Graduate School of Medicine, 1-4-3 Asahi-machi, Abeno-ku, Osaka, Japan. ²Department of Neurosurgery, Osaka City University Graduate School of Medicine, 1-4-3 Asahi-machi, Abeno-ku, Osaka, Japan.

Received: 26 June 2016 Accepted: 21 October 2016

Published online: 17 November 2016

\section{References}

1. Cushing H. Peptic ulcers and the inter-brain. Surg Gynecol Obste. 1932;55:1-34

2. Gupta S, Kaushik R, Sharma R, Attri A. The management of large perforations of duodenal ulcers. BMC Surg. 2005:5:15.

3. Rokitansky c. Handbuch der pathologischen Anatomie, vol. 2. Wien: Braumüller \& Seidel; 1846.

4. Brooks FP. Stress ulcer: etiology, diagnosis and treatment. Med Clin North Am. 1966:50(5):1447-55.

5. Leonard AS, Long D, French LA, Peter ET, Wangensteen OH. Pendular pattern in gastric secretion and blood flow following hypothalamic stimulation - origin of stress ulcer? Surgery. 1964;56:109-20.

6. Porter RW, Movius HJ, French JD. Hypothalamic influences on hydrochloric acid secretion of the stomach. Surgery. 1953;33(6):875-80.

7. French JD, Porter RW, Von Amerongen FK, Raney RB. Gastrointestinal hemorrhage and ulceration associated with intracranial lesions; a clinical and experimental study. Surgery. 1952;32(2):395-407.
8. Boles RS. Neurogenic factors in production of acute gasatric ulcer. JAMA. 1940;115(21):1771-3.

9. Hernandez DE. The role of brain peptides in the pathogenesis of experimental stress gastric ulcers. Ann N Y Acad Sci. 1990;597:28-35.

10. Spencer JA, Morlock CG, Sayre GP. Lesions in upper portion of the gastrointestinal tract associated with intracranial neoplasms. Gastroenterology. 1959;37(1):20-7.

11. Boey J, Choi SK, Poon A, Alagaratnam TT. Risk stratification in perforated duodenal ulcers. A prospective validation of predictive factors. Ann Surg. 1987;205(1):22-6.

12. Billing A, Frohlich D, Schildberg FW. Prediction of outcome using the Mannheim peritonitis index in 2003 patients. Peritonitis Study Group Br J Surg. 1994:81(2):209-13.

13. Qureshi AM, Zafar A, Saeed K, Quddus A. Predictive power of Mannheim Peritonitis Index. J Coll Physicians Surg Pak. 2005:15(11):693-6.

14. Demmel N, Maag K, Osterholzer G. The value of clinical parameters for determining the prognosis of peritonitis-validation of the Mannheim Peritonitis Index. Langenbecks Arch Chir. 1994;379(3):152-8.

15. Ahuja A, Pal R. Prognostic scoring indicator in evaluation of clinical outcome in intestinal perforations. J Clin Diagn Res. 2013;7(9):1953-5.

16. Mishra A, Sharma D, Raina VK. A simplified prognostic scoring system for peptic ulcer perforation in developing countries. Indian J Gastroenterol. 2003;22(2):49-53.

17. Surapaneni S, Rajkumar S, Reddy AV. The Perforation-Operation time Interval; An Important Mortality Indicator in Peptic Ulcer Perforation. J Clin Diagn Res. 2013;7(5):880-2

18. Kocer B, Surmeli S, Solak C, Unal B, Bozkurt B, Yildirim O, Dolapci M, Cengiz O. Factors affecting mortality and morbidity in patients with peptic ulcer perforation. J Gastroenterol Hepatol. 2007;22(4):565-70.

19. Tas I, Ulger BV, Onder A, Kapan M, Bozdag Z. Risk factors influencing morbidity and mortality in perforated peptic ulcer disease. Ulus Cerrahi Derg. 2015;31(1):20-5.

20. Boey J, Wong J, Ong GB. Bacteria and septic complications in patients with perforated duodenal ulcers. Am J Surg. 1982;143(5):635-9.

21. Bertleff MJ, Lange JF. Perforated peptic ulcer disease: a review of history and treatment. Dig Surg. 2010;27(3):161-9.

22. Cellan-Jones CJ. A rapid method of treatment in perforated duodenal ulcer. Br Med J. 1929;1(3571):1076-7.

23. Graham RR. The treatment of perforated duodenal ulcers. Surg Gynec Obstet. 1937;64:235-8.

24. Cienfuegos JA, Rotellar F, Valenti V, Arredondo J, Baixauli J, Pedano N, Bellver M, Hernandez-Lizoain JL. Giant duodenal ulcer perforation: a case of innovative repair with an antrum gastric patch. Rev Esp Enferm Dig. 2012; 104(8):436-9.

25. Chaudhary A, Bose SM, Gupta NM, Wig JD, Khanna SK. Giant perforations of duodenal ulcer. Indian J Gastroenterol. 1991;10(1):14-5.

26. Sharma D, Saxena A, Rahman H, Raina VK, Kapoor JP. 'Free omental plug': a nostalgic look at an old and dependable technique for giant peptic perforations. Dig Surg. 2000;17(3):216-8.

27. Mcllrath DC, Larson $\mathrm{RH}$. Surgical management of large perforations of the duodenum. Surg Clin North Am. 1971;51(4):857-61.

28. Lal P, Vindal A, Hadke NS. Controlled tube duodenostomy in the management of giant duodenal ulcer perforation: a new technique for a surgically challenging condition. Am J Surg. 2009;198(3):319-23.

29. Cranford Jr CA, Olson R, Bradley 3rd EL. Gastric disconnection in the management of perforated giant duodenal ulcer. Am J Surg. 1988; 155(3):439-42. 